\title{
Impact of Healthcare Delivery System Type on Clinical, Utilization, and Cost Outcomes of Patient-Centered Medical Homes: a Systematic Review
}

\author{
Clark A. Veet, $M D^{\top}$ D. Thomas R. Radomski, MD, MS', Christopher D'Avella, MD², \\ Inmaculada Hernandez, PharmD, PhD 3 , Charles Wessel, MLS4, Elizabeth C. S. Swart, BS ${ }^{5}$, \\ William H. Shrank, MD, MSHS ${ }^{6}$, and Natasha Parekh, MD, MS ${ }^{7}$
}

\begin{abstract}
'Department of Medicine Division of General Internal Medicine, University of Pittsburgh, Pittsburgh, PA, USA; ${ }^{2}$ Department of Medical Oncology, Fox Chase Cancer Center, Philadelphia, PA, USA; ${ }^{3}$ Department of Pharmacy and Therapeutics, University of Pittsburgh, Pittsburgh, PA, USA; ${ }^{4}$ Health Sciences Library System, University of Pittsburgh, Pittsburgh, PA, USA; ${ }^{5}$ UPMC Center for High-Value Healthcare, UPMC Insurance Services Division, Pittsburgh, PA, USA; ${ }^{6}$ Humana, Louisville, KY, USA; ${ }^{7}$ The Queen's Health System, Honolulu, HI, USA.
\end{abstract}

BACKGROUND: As healthcare reimbursement shifts from being volume to value-focused, new delivery models aim to coordinate care and improve quality. The patientcentered medical home (PCMH) model is one such model that aims to deliver coordinated, accessible healthcare to improve outcomes and decrease costs. It is unclear how the types of delivery systems in which PCMHs operate differentially impact outcomes. We aim to describe economic, utilization, quality, clinical, and patient satisfaction outcomes resulting from PCMH interventions operating within integrated delivery and finance systems (IDFS), government systems including Veterans Administration, and non-integrated delivery systems.

METHODS: We searched PubMed, the Cochrane Library, and Embase from 2004 to 2017. Observational studies and clinical trials occurring within the USA that met $\mathrm{PCMH}$ criteria (as defined by the Agency for Healthcare Research and Quality), addressed ambulatory adults, and reported utilization, economic, clinical, processes and quality of care, or patient satisfaction outcomes.

RESULTS: Sixty-four studies were included. Twenty-four percent were within IDFS, 29\% were within government systems, and $47 \%$ were within non-IDFS. IDFS studies reported decreased emergency department use, primary care use, and cost relative to other systems after PCMH implementation. Government systems reported increased primary care use relative to other systems after $\mathrm{PCMH}$ implementation. Clinical outcomes, processes and quality of care, and patient satisfaction were assessed heterogeneously or infrequently.

DISCUSSION: Published articles assessing PCMH interventions generally report improved outcomes related to utilization and cost. IDFS and government systems exhibit different outcomes relative to non-integrated systems,

Accepted for presentation at 2019 SGIM Annual Meeting (Washington, DC, May 8-11, 2019) and 2019 AcademyHealth Annual Research Meeting (Washington, DC, June 2-4, 2019)

Electronic supplementary material The online version of this article (https://doi.org/10.1007/s11606-019-05594-3) contains supplementary material, which is available to authorized users.

Received August 28, 2019

Revised November 18, 2019

Accepted December 2, 2019

Published online January 6, 2020 demonstrating that different health systems and populations may be particularly sensitive to PCMH interventions. Both the definition of PCMH interventions and outcomes measured are heterogeneous, limiting the ability to perform direct comparisons or meta-analysis.

KEY WORDS: patient-centered medical home; healthcare delivery models; health system science.

J Gen Intern Med 35(4):1276-84

DOI: $10.1007 / \mathrm{s} 11606-019-05594-3$

(c) Society of General Internal Medicine 2020

\section{BACKGROUND}

Improving the value and quality of healthcare in the USA is a public health priority. ${ }^{1}$ As the prevalence of chronic disease grows, individuals, employers, and insurers are seeking ways to reduce cost while improving healthcare quality and outcomes. Movement toward more coordinated care by implementing patient-centered medical homes (PCMHs) has been identified as a potential solution with more than 13,000 practices in the USA meeting National Committee for Quality Assurance (NCQA) PCMH recognition. ${ }^{2}$

A PCMH seeks to improve individual and population health outcomes by means of a multidisciplinary, coordinated primary care-based effort. The Agency for Healthcare Research and Quality (AHRQ) identifies five foundational elements of PCMH implementation including comprehensive care, patient-centeredness, coordinated care, accessible services, and quality and safety (Appendix 1). Previous systematic reviews that evaluated the implementation of PCMH interventions have reported mixed outcomes, such as slight reductions in emergency department (ED) visits but no reduction in hospital admissions or cost. ${ }^{3}$ However, many PCMH interventions occur within fragmented healthcare delivery systems where implementation can be difficult, compensation strategies vary, and outcome measure collection can be challenging. ${ }^{4}$ 
Since PCMH care delivery relies on coordinated and comprehensive services, the underlying health system may affect the ability of these care models to achieve their purported goal. For instance, the integrated delivery and finance system (IDFS) model - where a health plan and provider system are vertically integrated in one unified organization - is touted as providing better coordinated, higher quality care ${ }^{5-7}$ and may support PCMH goals more than other non-integrated models. Additionally, government-based systems including the Veteran Health Administration (VA) Patient Aligned Care Team (PACT) use team-based care delivered by employed providers, nurses, medical assistants, and staff to provide services. ${ }^{8}$ However, little is known if the success of a PCMH depends on the type of health system within which it is delivered.

We therefore sought to describe economic, utilization, clinical, processes and quality of care, and patient satisfaction outcomes resulting from PCMH interventions that were conducted within IDFS, government systems, and non-integrated delivery systems.

\section{METHODS}

\section{Registration, Data Sources, and Searches}

Prior to initiation of the systematic review, a formalized protocol was developed and registered in PROSPERO (PROSPERO 2017 CRD42017056972). A health science librarian (CBW) developed the search strategy with input from authors and by using as basis the search strategy used in a recent peerreviewed systematic review of PCMHs. ${ }^{3}$ Searches were executed in PubMed (Bethesda, MD: National Library of Medicine (US), National Center for Biotechnology Information), EMBASE.com (Elsevier Life Sciences IP Limited), and the following Cochrane Library (John Wiley and Sons) databases: Cochrane Database of Systematic Reviews (CDSR): Issue 3 of 12, March 2017; Database of Abstracts of Reviews of Effect (DARE): Issue 2 of 4, April 2015; Cochrane Central Register of Controlled Trials (TRIALS): Issue 2 of 12, February 2017; Cochrane Methodology Register: Issue 3 of 4, July 2012; Health Technology Assessment Database (HTAD): Issue 4 of 4, October 2016; and NHS Economic Evaluation Database (NHSEED): Issue 2 of 4, April 2015 (Appendix 4). On March 28, 2017, final database searches were run, results imported into an EndNote Library, and duplicate records removed. The EndNote Library was imported into DistillerSR ${ }^{\circledR}$ (Evidence Partners-Ottawa, Canada), a web-based software that aids in screening and data extraction.

\section{Study Selection}

We included peer-reviewed primary literature that evaluated interventions meeting the AHRQ definition of PCMH (Appendix 1) and were delivered to adults in the primary care setting. Articles comprised randomized control trials and observational studies. Practice settings included internal medicine, family medicine, or geriatric clinics. Studies were excluded if they were only qualitative in nature, secondary literature, or if they addressed provider, staff, or resident education initiatives only. To maximize the generalizability of studies, we excluded studies occurring within a diseasespecific specialty clinic (e.g., hypertension or diabetes-only clinics). Though study interventions had to meet NCQA PCMH criteria, article study sites did not need to be explicitly recognized by the NCQA as certified PCMH. This decision mirrored previous systematic reviews ${ }^{3}$ and was intended to allow for a more representative sample of practice settings with varying implementation.

In our search query, we incorporated the concepts of PCMHs, components of PCMHs, medical conditions and diseases, and the settings in which these diseases were treated (Appendix 2). The queries utilized the appropriate controlled vocabulary of each database along with keywords and phrases in the applicable search fields. Limits included a comprehensive query for eligible study designs; a query to eliminate letters, case reports, editorials, and other publication types; and a 2004 to 2017 publication year limit. We chose to include publications after 2004 since this is when the American Academy of Family Practice first recommended the adoption of $\mathrm{PCMH}$ in clinical practice.

The application of this query yielded 13,938 articles. We conducted 3 screening levels prior to data abstraction. In two screening levels, two investigators independently reviewed each title and abstract for relevance to the research questions and inclusion and exclusion criteria. In level three, one investigator reviewed full text versions of all included articles. Disagreements were resolved through review and discussion among investigators.

Study quality was assessed according to study type by two reviewers. Randomized control trials were assessed with Cochrane Risk of Bias tool version $1,{ }^{9}$ while observational studies, including quasi-experimental studies, were assessed with the Newcastle Ottawa tool. ${ }^{10}$

\section{Definition of Health Systems}

To achieve the goal of comparing IDFS, government, and nonIDFS studies, all included articles were required to provide information needed to ascertain the type of healthcare system. We screened articles for health system name and location, which was reported by the author within the body of the article. If health system name or location was absent from the abstract, we performed full text review to identify this information. If study sites and locations were named but there was no mention of type of system, the sites were individually cross referenced to an existing list (Appendix 3) of known IDFS. $^{7}$ Articles were excluded when no identifiable health system model or location was described. We defined government systems as Veterans Health Administration (VA), Military Health System, or Indian Health Service. Studies that did 
not meet inclusion status for IDFS or government system but included study site were categorized as non-IDFS. We included studies that demonstrated the use of at least one PCMH intervention (Appendix 1) as identified by reviewers. In VA health system studies, the patient aligned care team (PACT) was considered to be analogous to PCMHs.

\section{Data Extraction and Quality Assessment}

One investigator abstracted the data from each full text article chosen for inclusion. Extraction forms were pilot-tested with a sample of included articles by investigators to ensure that all relevant data were captured and to ensure reproducibility among abstractors. Data extraction forms included fields on study design, study population, interventions, health system status, geographic location, study methods, study quality, and study outcomes.

\section{Data Synthesis and Analysis}

For study outcomes, we identified five major outcome domains of interest a priori, including utilization (e.g., hospitalizations, emergency department (ED) use, primary and specialty care use), costs (e.g., total cost of care, hospital cost, pharmacy cost), processes of care (e.g., quality indicators for diseases, preventative care including cancer screening), clinical outcomes (e.g., mortality, blood pressure, lipid levels), and patient satisfaction. Investigators categorized each outcome into one of these domains (Table 1).

\section{RESULTS}

A systematic search of PubMed, the Cochrane Library, and Embase from 2004 to April 2017 yielded 13,939 unique publications. Sixty-four studies were included, of which 15 (24\%) were IDFS-based, 19 (29\%) were government-based, and $30(47 \%)$ were non-IDFS-based (Figure 1).

Table 1 Selected Study Domains and Outcomes Recorded

\begin{tabular}{|c|c|}
\hline Domain & Outcomes reported \\
\hline Utilization & $\begin{array}{l}\text { Emergency department (ED) visits, hospital admis- } \\
\text { sions, ambulatory primary care visits, ambulatory } \\
\text { specialty care visits, readmissions }\end{array}$ \\
\hline Economic & $\begin{array}{l}\text { Total cost, inpatient cost, outpatient cost, pharmacy } \\
\text { cost }\end{array}$ \\
\hline Process of care & $\begin{array}{l}\text { Hemoglobin A1c testing in patients with diabetes } \\
\text { mellitus (DM), colorectal cancer screening, lipid } \\
\text { screening in DM, nephropathy screening in DM, } \\
\text { retinopathy screening in DM, foot examination in } \\
\text { DM, flu vaccination, pneumonia vaccination, } \\
\text { depression screening, colorectal cancer (CRC) } \\
\text { screening, breast cancer screening }\end{array}$ \\
\hline Clinical & $\begin{array}{l}\text { Mortality, pain score, BP control, Hemoglobin A1c } \\
\text { measurement, ESRD in DM, amputation in DM, end } \\
\text { stage renal disease (ESRD) in DM, acute myocardial } \\
\text { infarction (AMI) in DM, cerebrovascular event } \\
\text { (CVA) in DM, depression scores }\end{array}$ \\
\hline $\begin{array}{l}\text { Patient } \\
\text { experience }\end{array}$ & Patient satisfaction scores \\
\hline
\end{tabular}

For primary outcomes, we compiled and assessed the number of studies that addressed each domain within each type of health system. Among the 64 studies, utilization was most frequently reported $(47,74 \%)$, followed by economic $(25$, $39 \%$ ) outcomes, processes of care $(16,25 \%)$, clinical outcomes $(16,25 \%)$, and patient satisfaction $(5,9 \%)$. Outcome domains and individual outcomes are reported in Table 2.

\section{Utilization Outcomes}

Utilization outcomes were most commonly reported among included studies (Table 1, Figure 2), with $74 \%$ of studies reporting ED visits, hospitalizations, readmissions, or ambulatory visits (primary care and/or specialty care visits).

ED utilization was addressed in 35 (54.7\%) studies (8 IDFS, 11 government, and 16 non-IDFS). Among studies that assessed PCMHs within IDFS, 6 of $8(75 \%)$ reported less ED use ${ }^{11-16}$ whereas 5 of $11(45.4 \%)$ government ${ }^{17-21}$ and 6 of $16(37.5 \%)$ of non-IDFS studies ${ }^{22-27}$ reported less ED use. Hospitalization was assessed in 31 (48.4\%) studies (7 IDFS, 12 government, and 12 non-IDFS). Among IDFS studies, 2 of $8(25 \%)$ reported less hospitalizations ${ }^{11,15}$ whereas 5 of 12 $(50 \%)$ government $^{17,21,28-30}$ and 3 of $12(35 \%)$ non-IDFS studies $^{23,} 25,{ }^{26}$ reported fewer hospitalizations with PCMH implementation.

Primary care utilization was assessed in 17 (26.5\%) studies (4 IDFS, 6 government, and 7 non-IDFS). All 4 IDFS studies $^{11,12,14,16}$ reported less primary care use with PCMH interventions whereas 0 of $6(0 \%)$ government and only 1 of $7(14.3 \%)$ non-IDFS studies ${ }^{31}$ reported fewer primary care visits. Outpatient specialty care use of patients was assessed in $14(21.9 \%)$ studies (3 IDFS, 4 government, and 7 nonIDFS). Among studies assessing PCMHs within IDFS, 1 of 3 $(33 \%)$ reported less specialty use ${ }^{11}$ whereas 2 of $4(50 \%)$ government $^{28,32}$ and only 1 of 7 (14.3\%) non-IDFS studies ${ }^{33}$ reported fewer specialty care visits. Utilization outcomes are represented graphically in Figure 2. Additional utilization outcomes are included in Appendix 9.

\section{Economic Outcomes}

Economic outcomes were reported in 26 (41\%) studies, with total cost of care being the most commonly reported (8 IDFS, 5 government, and 12 non-IDFS). Total cost of care calculations varied according to study and tended to represent cost to the health system. Among studies assessing PCMHs within IDFS, 4 of $8(50 \%)$ reported lower $\operatorname{cost}^{11,13,34,35}$ whereas 3 of $5(60 \%)$ government $^{30,36,37}$ and 4 of $12(33.3 \%)$ non-IDFS studies $^{23,38-40}$ reported lower cost with PCMH interventions. Total cost outcomes are represented graphically in Figure 2. Additional economic outcomes are included in Appendix 9.

\section{Clinical Outcomes}

Eleven (17.1\%) studies (4 IDFS, 5 government, and 3 nonIDFS) reported on clinical outcomes in PCMHs. Most studies 


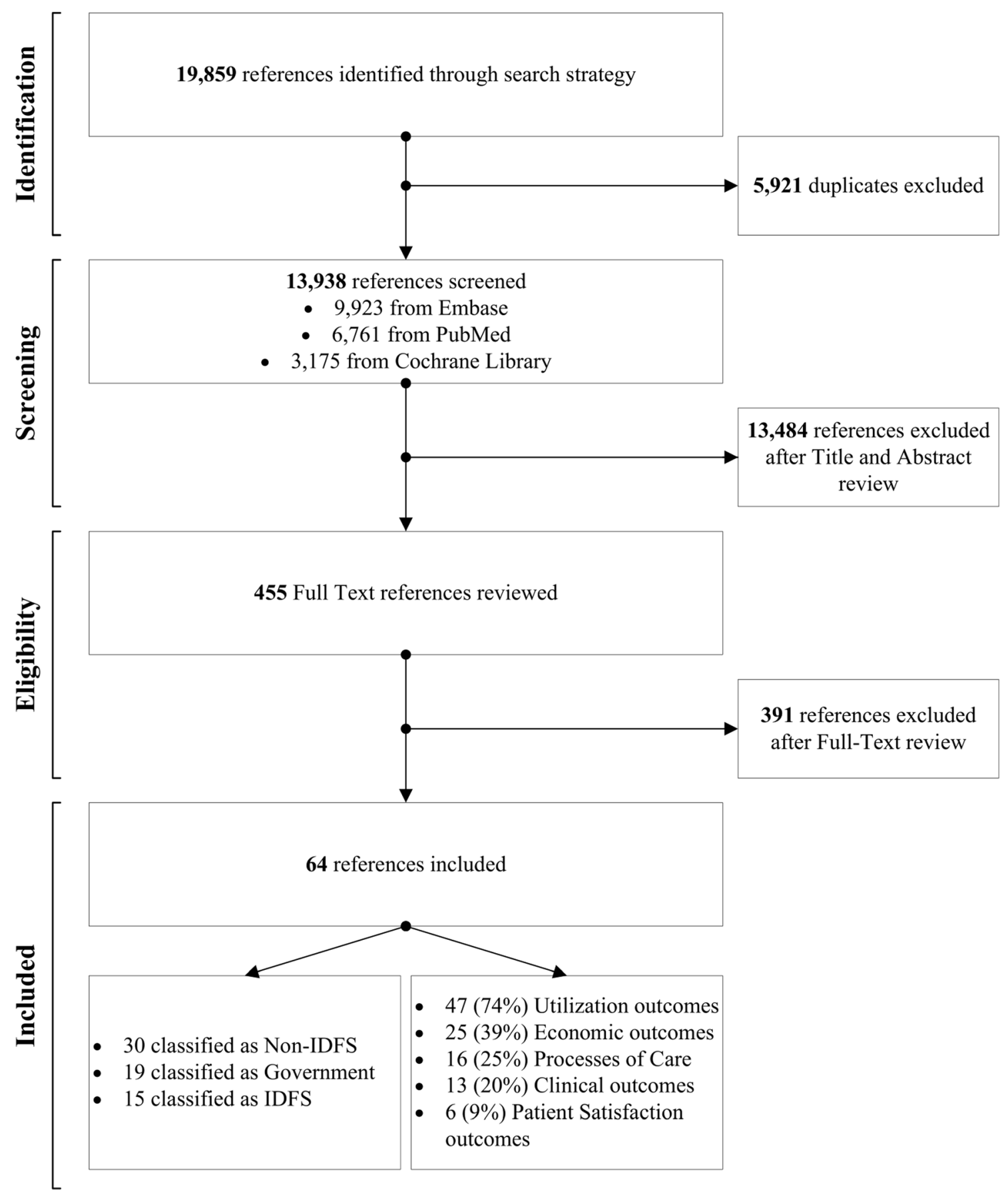

Figure 1 Flow diagram of systematic review.

reported on multiple clinical outcomes including HgbAlc, blood pressure, lipid levels, death, pain, and quality of life. Among IDFS studies, 4 of 4 (100\%) reported improvement in at least one outcome measure ${ }^{41-44}$ whereas 4 of $5(80 \%)$ government $^{18,29,45,46}$ and 2 of $4(50 \%)$ of non-IDFS studies $^{47,48}$ reported improvement, respectively. HgbAlc was most commonly reported and significantly improved in all studies assessing PCMHs within IDFS and government systems ${ }^{29,43,46}$ Mortality was reported in only 2 studies $^{32,44}$ and was significantly reduced in only IDFS. ${ }^{44}$ Additional clinical outcomes are included in Appendix 9.

\section{Processes of Care 9}

Processes of care indicators were reported in $16(25 \%)$ studies (4 IDFS studies, ${ }^{11,15,43,49} 3$ government studies, ${ }^{20,29,50}$ and 9 non-IDFS. ${ }^{33,}{ }^{51-57}$ Most commonly, these studies reported on standard quality metrics in the care of diabetes and cancer screening. Diabetes-related indicators such as nephropathy and retinopathy screening were reported in 2 IDFS-based studies, ${ }^{43,} 462$ government-based studies, ${ }^{20,} 29$ and 6 nonIDFS-based studies with improvements reported across all delivery systems types. Depression screening, vaccination rates, chlamydia screening, appropriate follow-up interval 
Table 2 Studies with Outcomes Reported, by Health System Status $(n, \%)$

\begin{tabular}{|c|c|c|c|}
\hline & $\begin{array}{l}\text { Integrated } \\
\text { delivery } \\
\text { and } \\
\text { finance } \\
\text { system }\end{array}$ & $\begin{array}{l}\text { Non- } \\
\text { integrated } \\
\text { delivery and } \\
\text { finance } \\
\text { system }\end{array}$ & $\begin{array}{l}\text { Government } \\
\text { system }\end{array}$ \\
\hline Utilization $(n=47)$ & $8(17)$ & $20(46.9)$ & $17(36.1)$ \\
\hline - ED visits $(n=35)$ & $8(23)$ & $16(46)$ & $11(31)$ \\
\hline $\begin{array}{l}\text { - Admissions } \\
(n=31)\end{array}$ & $7(24)$ & $12(38)$ & $12(38)$ \\
\hline $\begin{array}{l}\text { - PCP visits } \\
(n=17)\end{array}$ & $4(24)$ & $7(41)$ & $6(35)$ \\
\hline $\begin{array}{l}\text { - Specialty visits } \\
(n=14)\end{array}$ & $3(21)$ & $7(50)$ & $4(29)$ \\
\hline Economic $(n=25)$ & $8(38)$ & $11(44)$ & $5(20)$ \\
\hline $\begin{array}{l}\text { - Total cost } \\
(n=25)\end{array}$ & $8(38)$ & $11(44)$ & $5(20)$ \\
\hline $\begin{array}{l}\text { Processes of care } \\
(n=16)\end{array}$ & $4(25)$ & $9(56.2)$ & $3(18.8)$ \\
\hline $\begin{array}{l}\text { Clinical outcomes } \\
(n=16)\end{array}$ & $4(33.3)$ & $4(33.3)$ & $4(33.3)$ \\
\hline $\begin{array}{l}\text { Patient satisfaction } \\
(n=6)\end{array}$ & $2(33.3)$ & $2(50)$ & $1(33.3)$ \\
\hline
\end{tabular}

after hospitalization, and guideline-based medication prescription were included in 2 or less studies.

For cancer screening, only 1 IDFS-based study reported on this outcome $e^{49}$ and showed improvement in colorectal cancer (CRC) screening rates. Two of 5 (40\%) non-IDFS-based studies reporting breast cancer screening showed an improvement in screening rates, ${ }^{24,55}$ while 1 of $5(20 \%)$ non-IDFS studies reporting CRC screening showed an improvement in screening rates. ${ }^{33}$ No included government studies reported cancer screening as an outcome.

\section{Patient Experience}

Only 9\% (6 of 64) of studies included patient experience outcomes. These included IDFS studies, ${ }^{14,}{ }^{58} 1$ government study, ${ }^{59}$ and 3 non-IDFS studies. ${ }^{19,} 60,61$ One IDFS study ${ }^{58}$ reported a significant increase in patient's perception of quality, care coordination, service, and care by a PCP or ED provider after PCMH implementation. Another IDFS study ${ }^{14}$ reported increases in access to care and coordination at 1 and 2 years after PCMH implementation, but no significant difference in patient activation, quality of doctor-patient interaction, staff helpfulness, or goal setting. The sole government study ${ }^{59}$ reported significant increases in all 11 patient experience domains after implementation of the PCMH model. All 3 non-IDFS studies ${ }^{19,} 60,61$ reported improvement in the majority of reported outcomes. A full description of patient experience outcomes is included in Appendix 9.

\section{DISCUSSION}

In our systematic review of the impact of PCMH implementation within multiple types of health systems, we found variable impact of PCMH implementation on key outcomes.
However, certain patterns emerged when describing health system delivery type and PCMH success. Utilization of acute care services including ED use and hospitalizations decreased in the majority of studies across all care systems, and a higher proportion of IDFS studies reported decreased ED utilization compared with other studies. Furthermore, within the ambulatory care setting, all 6 government studies reported increased primary care use as a result of the PCMH, whereas all 4 IDFS studies reported less PCP use. Total cost of care was reported to be lower in half of IDFS-related studies and two-thirds of government studies, but only one-third of non-IDFS studies. Clinical outcomes, quality and processes or care, and patient satisfaction outcomes varied between systems and were infrequently reported.

Two existing systematic reviews ${ }^{3,62}$ have examined the effects of PCMHs; however, none to our knowledge has reported findings by type of health system type. A review of 19 comparative studies by Jackson et al. ${ }^{3}$ reported small but significant positive effects of PCMH implementation on patient experience and small to moderate positive effects on preventive services, but it did not report cost savings. Sinaiko et al. ${ }^{62}$ reported a small reduction in specialty care, improvements in breast and cervical cancer screening, and decreased spending in $11 \mathrm{PCMH}$ initiatives. Our study provides granularity by showcasing differences among health systems, in particular highlighting differential outcomes for ED and primary care and cost outcomes.

Regarding utilization, about half of our included studies reported decreased ED utilization in the context of PCMH interventions, which is consistent with prior reviews/metaanalyses. ${ }^{3}$ Yet, half of studies in our review reported no significant change or an increase in ED utilization. This discordance could potentially be explained by variability in access to care, less effective PCMH implementation, or sicker patient populations. Prior research suggests that PCMHs provide increased access to care for vulnerable populations who have historically not sought care, potentially leading to increased utilization for previously disengaged patients (i.e., the "woodwork" phenomenon $\left(46,{ }^{63}\right)$. Our observation that a larger proportion of IDFS-based studies demonstrated reduced ED use suggests that alignment of payer and provider systems leads to more effective care coordination and appropriate utilization relative to non-IDFS.

In our review, one of the striking differences across health systems related to increased primary care use in all VA-based studies and decreased use in IDFS-based studies. Prior research on the effect of the VA-based PACT model ${ }^{36}$ has demonstrated similarly increased primary care use, particularly among veterans age 65 or older. The increase in utilization may result from population health strategies targeting PCP use or an influx in VA care that was previously obtained in civilian settings. The VA patient population may also be more sensitive to the types of interventions that PCMHs employ and may be more likely to engage in primary. In our review, primary care use decreased in all four IDFS-based studies. While this 


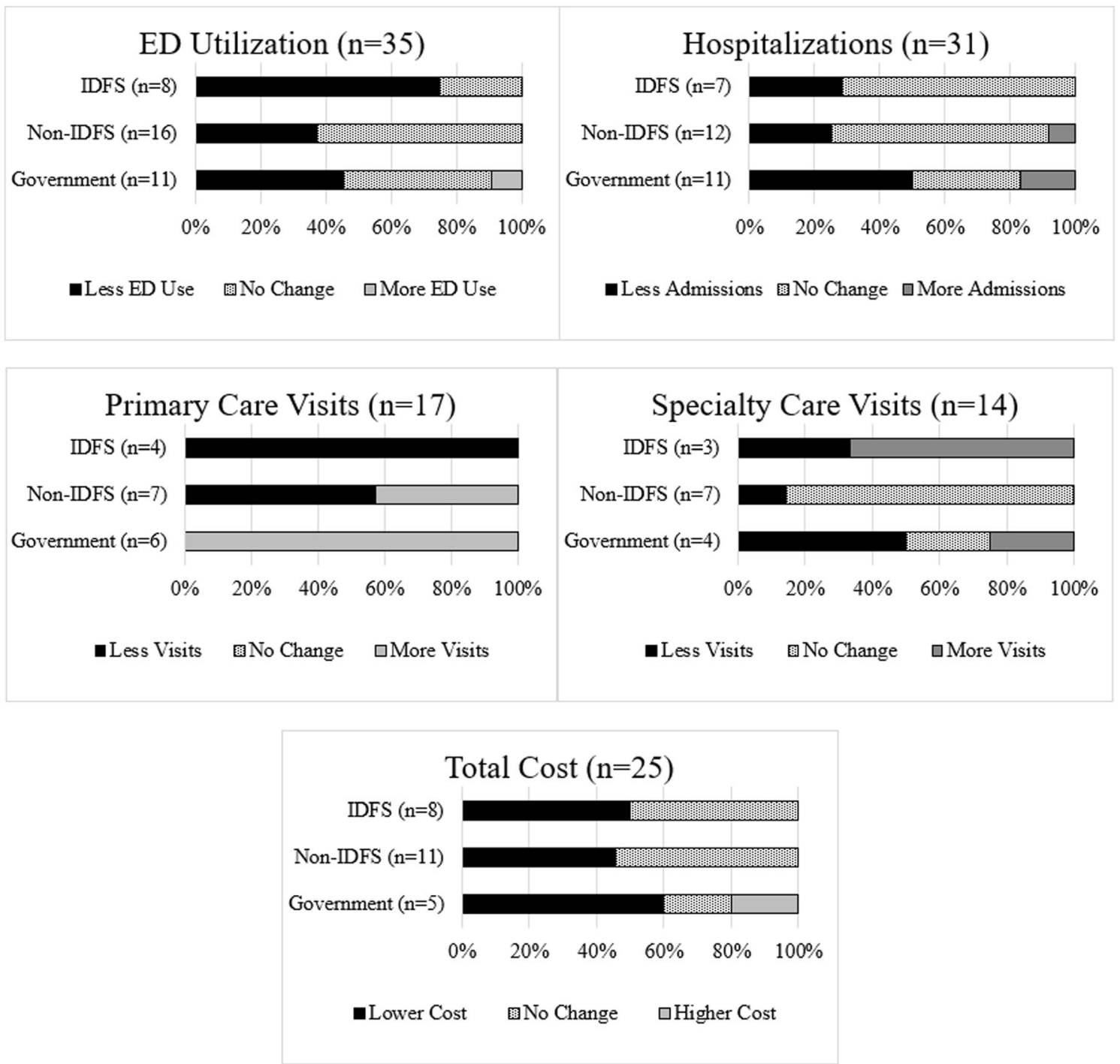

Figure 2 Outcomes of PCMH interventions.

finding must be interpreted with caution given the small sample size, components including secure messaging and telehealth have reduced primary care use. ${ }^{68}$

Economic outcomes were also heavily reported. Studies in IDFS and non-IDFS systems generally reported statistically significant cost savings or no change in total costs after implementation of PCMH interventions. Other systematic reviews have shown similar results regarding cost. Jackson et al. $^{3}$ observed no change in cost, whereas Sinaiko et al. ${ }^{63}$ reported no change across all patients but a $4.2 \%$ cost reduction in a higher-morbidity subgroup. Two IDFS-based studies measuring cost at different time points ${ }^{13,35}$ showed no cost savings at year 1; however, at year 2 , both showed cost savings. These findings are consistent with other studies where cost savings were generally not evident until years 2 or $3 .^{34}$ Given that many PCMH interventions required additional staffing or information technology infrastructure, the initial startup cost is often absorbed into the first year cost calculations. While most government studies showed cost savings or no change, one high-quality VA study ${ }^{64}$ reported an increase in total cost due to a particularly costly, high-risk group of patients with multiple comorbidities. A quarter of studies in our review reported on clinical or quality outcomes. Clinical outcomes, reported in $25 \%$ of studies, were common measures used in monitoring chronic diseases including hypertension, diabetes, and hyperlipidemia. In IDFS-based studies, all four studies reported improvement in at least one outcome compared with $80 \%$ of government and $50 \%$ of non-IDFS studies. However, there were very few studies in general reporting clinical outcomes and direct comparison based on these proportions is limited. Of all clinical outcomes, HgbAlc was most commonly reported and improved in all IDFS and government studies. ${ }^{29,43,46}$ While our review identified many studies that reported statistically significant improvement across an array of clinical values, clinical significance of these findings is questionable.

Patient satisfaction was the least frequently reported outcome in our review. Though sparsely and heterogeneously reported, all studies showed patient satisfaction outcomes remained stable or improved. Given increased attention to 
payment linked to patient-reported outcome measures, this finding in itself may provide rationale for future PCMH uptake. As patient satisfaction and patient-reported outcomes become increasingly linked to successful disease management and reimbursement, ${ }^{65}$ it is important that these measures be included in future evaluations of health system interventions. Furthermore, it is also necessary that research be performed using standardized patient-centered tools to ensure accurate comparison. $^{66}$

\section{LIMITATIONS}

This study has notable limitations. First, there is tremendous variability and heterogeneity in reporting of methods and outcomes. This does not appear to be unique to our study design or search string and has been recognized within the PCMH literature. $^{2,}{ }^{67}$ This prevented us from completing metaanalysis or statistical comparison between health system delivery types. Future works aiming to perform statistical comparison of outcomes may benefit from standardized measurement and reporting of cost, utilization, and patient-reported outcomes. Second, this study is subject to publication bias. When comparing health systems, entities like VA are beholden to Congress and taxpayers in reporting findings from federally funded initiatives with either positive or negative outcomes. Other health systems may preferentially publish positive outcomes. Third, while we attempted to compare how healthcare delivery models influenced the success of PCMH interventions, not all health systems or care models are the same. The heterogeneity among IDFS across the country makes it difficult for the studies that we included to be representative of this care delivery system as a whole. Fourth, the degree of PCMH implementation may vary, leading to washout of successful outcomes. ${ }^{67}$ The variability in adoption of PCMH principles may provide insight into the mixed results of PCMHs in prior literature as well as this study. ${ }^{68}$ Finally, the clinical sites chosen to participate in a PCMH intervention, many of which were pilot tests, may not be representative of all clinical sites within a health system. Given the paucity of randomized clinical trials in our review, it is possible the sites were selected due to their higher performance or increased engagement in the PCMH model at baseline.

\section{CONCLUSION}

We assessed the outcomes of PCMH interventions implemented within IDFS-based, government-based, and nonIDFS-based systems. As expected, outcomes were heterogeneous; however, acute care utilization and cost decreased or did not change in the majority of all studies across systems. Notably, government systems appeared particularly sensitive to PCMH interventions with increased primary care use compared with IDFS and non-IDFS studies. Many studies have not reported on clinical or quality outcomes in the context of
PCMH interventions and the vast majority of studies did not address patient satisfaction. This study has important implications for health systems and policymakers assessing the effectiveness of PCMH interventions and provides contextual understanding of system-based factors augmenting the success of PCMH interventions.

Acknowledgments: The authors thank Etsemaye P. Agonafer MD, MPH, Brendan Filardo MD, Amy J. Kennedy MD, Michael Simonson $M D$, and Alexander Teng MD who contributed to early article screening and Jennifer Corbelli MD, MS for help with study design and risk of bias assessment.

Corresponding Author: Clark A. Veet, MD; Department of Medicine Division of General Internal Medicine University of Pittsburgh, Pittsburgh, PA, USA (e-mail: veetca@upmc.edu).

Funding Information CAV is supported by NCATS TL-1 (TROO1858). TR was supported by K12 TR0001856.

Registration: PROSPERO 2017 CRD42017056972 2.

\section{Compliance with Ethical Standards:}

Conflict of Interest: The authors declare that they have no conflict of interest.

\section{REFERENCES}

1. Institute of Medicine (US) Roundtable on Value \& Science-Driven Health Care. Value in Health Care: Accounting for Cost, Quality, Safety, Outcomes, and Innovation. Washington (DC) National Academies Press (US)

2. Assurance NCfQ;Pageshttps://www.ncqa.org/programs/health-careproviders-practices/patient-centered-medical-home-pcmh/ on June 1 2019.

3. Jackson GL, Powers BJ, Chatterjee R, Bettger JP, Kemper AR, Hasselblad V, et al. The patient centered medical home. A systematic review. Ann Intern Med 2013;158(3):169-78.

4. Solberg LI, Crain AL, Tillema JO, Fontaine PL, Whitebird RR, Flottemesch TJ, et al. Challenges of medical home transformation reported by 118 patient-centered medical home (PCMH) leaders. J Am Board Fam Med 2014;27(4):449-57.

5. Enthoven AC. Integrated delivery systems: the cure for fragmentation. Am J Manag Care 2009; 15(10 Suppl):S284-90.

6. Johnson G, Lyon ZM, Frakt A. Provider-Offered Medicare Advantage Plans: Recent Growth And Care Quality. Health Aff 2017;36(3):539-47.

7. Parekh N, Hernandez I, Radomski TR, Shrank WH. Relationships between provider-led health plans and quality, utilization, and satisfaction. Am J Manag Care 2018;24(12):628-32.

8. Yano EM, Bair MJ, Carrasquillo O, Krein SL, Rubenstein LV. Patient Aligned Care Teams (PACT): VA's journey to implement patient-centered medical homes. J Gen Intern Med 2014;29 Suppl 2:S547-9.

9. Werner RM, Canamucio A, Shea JA, True G. The medical home transformation in the Veterans Health Administration: an evaluation of early changes in primary care delivery. Health Serv Res 2014;49(4):132947.

10. Higgins JP, Altman DG, Gotzsche PC, Juni P, Moher D, Oxman AD, et al. The Cochrane Collaboration's tool for assessing risk of bias in randomised trials. BMJ 2011;343:d5928.

11. Wells G, Shea B, O'Connell D, Peterson J, Welch V, Losos M, et al. 2012;Pages http://www.ohrica/programs/clinical_epidemiology/oxfordasp on June 262019

12. Reiss-Brennan B, Brunisholz KD, Dredge C, Briot P, Grazier K, Wilcox A, et al. Association of Integrated Team-Based Care With Health Care Quality, Utilization, and Cost. Jama 2016;316(8):826-34.

13. Reid RJ, Johnson EA, Hsu C, Ehrlich K, Coleman K, Trescott C, et al. Spreading a medical home redesign: effects on emergency department use and hospital admissions. Ann Fam Med 2013;11 Suppl 1:S19-26. 
14. Rosenberg CN, Peele P, Keyser D, McAnallen S, Holder D. Results from a patient-centered medical home pilot at UPMC Health Plan hold lessons for broader adoption of the model. Health Aff. 2012;31(11):2423-31.

15. Fishman PA, Johnson EA, Coleman K, Larson EB, Hsu C, Ross TR, et al. Impact on seniors of the patient-centered medical home: evidence from a pilot study. Gerontologist 2012;52(5):703-11.

16. Gilfillan RJ, Tomcavage J, Rosenthal MB, Davis DE, Graham J, Roy JA, et al. Value and the medical home: effects of transformed primary care. Am J Manag Care. 2010;16(8):607-14. 16

17. Reid RJ, Fishman PA, Yu O, Ross TR, Tufano JT, Soman MP, et al. Patient-centered medical home demonstration: a prospective, quasiexperimental, before and after evaluation. Am J Manag Care 2009; 15(9):e71-87.

18. O'Toole TP, Johnson EE, Aiello R, Kane V, Pape L. Tailoring Care to Vulnerable Populations by Incorporating Social Determinants of Health: the Veterans Health Administration's "Homeless Patient Aligned Care Team" Program. Prev Chronic Dis 2016;13:E44.

19. Andrews CA, Northam S, Gosselin K. Evaluation of an Innovative Program To Improve Outcomes among Military Beneficiaries with Diabetes. Nurs Econ 2015;33(5):271-80.

20. Fandre M, McKenna C, Beauvais B, Kim F, Mangelsdorff AD. Patientcentered medical home implementation effects on emergency room utilization: a case study. Hosp Top 2014;92(3):59-65.

21. Smith JJ, Johnston JM, Hiratsuka VY, Dillard DA, Tierney S, Driscoll DL. Medical home implementation and trends in diabetes quality measures for AN/AI primary care patients. Prim Care Diabetes 2015;9(2):120-6.

22. Johnston JM, Smith JJ, Hiratsuka VY, Dillard DA, Szafran QN Driscoll DL. Tribal implementation of a patient-centred medical home model in Alaska accompanied by decreased hospital use. Int J Circumpolar Health 2013;72.

23. Newman RJ, Bikowski R, Nakayama K, Cunningham T, Acker $\mathbf{P}$, Bradshaw D. Outcomes of Embedded Care Management in a Family Medicine Residency Patient-Centered Medical Home. Fam Med 2017;49(1):46-51

24. Cuellar A, Helmchen LA, Gimm G, Want J, Burla S, Kells BJ, et al. The CareFirst Patient-Centered Medical Home Program: Cost and Utilization Effects in Its First Three Years. J Gen Intern Med 2016;31(11):1382-8.

25. Rosenthal MB, Alidina S, Friedberg MW, Singer SJ, Eastman D, Li Z, et al. A Difference-in-Difference Analysis of Changes in Quality, Utilization and Cost Following the Colorado Multi-Payer Patient-Centered Medical Home Pilot. J Gen Intern Med 2016;31(3):289-96.

26. Carrillo JE, Carrillo VA, Guimento R, Mucaria J, Leiman J. The NewYork-Presbyterian Regional Health Collaborative: a three-year progress report. Health Aff. 2014;33(11):1985-92.

27. Carrillo JE, Shekhani NS, Deland EL, Fleck EM, Mucaria J, Guimento $\mathbf{R}$, et al. A regional health collaborative formed By NewYork-Presbyterian aims to improve the health of a largely Hispanic community. Health Aff. 2011;30(10):1955-64.

28. Roby DH, Pourat N, Pirritano MJ, Vrungos SM, Dajee H, Castillo D, et al. Impact of patient-centered medical home assignment on emergency room visits among uninsured patients in a county health system. Med Care Res Rev 2010;67(4):412-30.

29. Randall I, Mohr DC, Maynard C. VHA Patient-Centered Medical Home Associated With Lower Rate of Hospitalizations and Specialty Care Among Veterans With Posttraumatic Stress Disorder. J Healthc Qual 2015.

30. O'Toole TP, Buckel L, Bourgault C, Blumen J, Redihan SG, Jiang L, et al. Applying the chronic care model to homeless veterans: effect of a population approach to primary care on utilization and clinical outcomes. Am J Public Health. 2010;100(12):2493-9. 17

31. Edes T, Kinosian B, Vuckovic NH, Olivia Nichols L, Mary Becker M, Hossain M. Better access, quality, and cost for clinically complex veterans with home-based primary care. J Am Geriatr Soc 2014;62(10): 1954-61

32. Romanelli RJ, Leahy A, Jukes T, Ishisaka DY. Pharmacist-led medication management program within a patient-centered medical home. Am J Health Syst Pharm 2015;72(6):453-9.

33. Yoon J, Chow A, Rubenstein LV. Impact of Medical Home Implementation Through Evidence-based Quality Improvement on Utilization and Costs. Med Care 2016;54(2):118-25.

34. Kern LM, Edwards A, Kaushal R. The Patient-Centered Medical Home and Associations With Health Care Quality and Utilization: A 5-Year Cohort Study. Ann Intern Med 2016;164(6):395-405.

35. Maeng DD, Khan N, Tomcavage J, Graf TR, Davis DE, Steele GD. Reduced acute inpatient care was largest savings component of Geisinger
Health System's patient-centered medical home. Health Aff. 2015;34(4):636-44.

36. Maeng DD, Graham J, Graf TR, Liberman JN, Dermes NB, Tomcavage $\mathbf{J}$, et al. Reducing long-term cost by transforming primary care: evidence from Geisinger's medical home model. Am J Manag Care 2012;18(3):14955.

37. Hebert PL, Liu CF, Wong ES, Hernandez SE, Batten A, Lo S, et al. Patient-centered medical home initiative produced modest economic results for Veterans Health Administration, 2010-12. Health Aff 2014;33(6):980-7.

38. Schubert CC, Myers LJ, Allen K, Counsell SR. Implementing Geriatric Resources for Assessment and Care of Elders Team Care in a Veterans Affairs Medical Center: Lessons Learned and Effects Observed. J Am Geriatr Soc 2016;64(7):1503-9.

39. Shane DM, Nguyen-Hoang P, Bentler SE, Damiano PC, Momany ET Medicaid Health Home Reducing Costs and Reliance on Emergency Department: Evidence From Iowa. Med Care 2016;54(8):752-7.

40. Jones C, Finison K, McGraves-Lloyd K, Tremblay T, Mohlman MK, Tanzman B, et al. Vermont's Community-Oriented All-Payer Medical Home Model Reduces Expenditures and Utilization While Delivering High-Quality Care. Popul Health Manag 2016;19(3): 196-205.

41. Fillmore H, DuBard CA, Ritter GA, Jackson CT. Health care savings with the patient-centered medical home: Community Care of North Carolina's experience. Popul Health Manag 2014;17(3):141-8.

42. Maeng DD, Graf TR, Davis DE, Tomcavage J, Bloom FJ. Can a patientcentered medical home lead to better patient outcomes? The quality implications of Geisinger's ProvenHealth Navigator. Am J Med Qual 2012;27(3):210-6.

43. Katon W, Russo J, Lin EH, Schmittdiel J, Ciechanowski P, Ludman E, et al. Cost-effectiveness of a multicondition collaborative care intervention: a randomized controlled trial. Arch Gen Psychiatry 2012;69(5):50614.

44. Liss DT, Fishman PA, Rutter CM, Grembowski D, Ross TR, Johnson EA, et al. Outcomes among chronically ill adults in a medical home prototype. Am J Manag Care 2013;19(10):e348-58.

45. Graham J, Bowen TR, Strohecker KA, Irgit K, Smith WR. Reducing mortality in hip fracture patients using a perioperative approach and "Patient- Centered Medical Home" model: a prospective cohort study. Patient Saf Surg. 2014;8(1):7. 18

46. Bekelman DB, Plomondon ME, Carey EP, Sullivan MD, Nelson KM, Hattler B, et al. Primary Results of the Patient-Centered Disease Management (PCDM) for Heart Failure Study: A Randomized Clinical Trial. JAMA Intern Med 2015; 175(5):725-32.

47. O'Toole TP, Pirraglia PA, Dosa D, Bourgault C, Redihan S, O'Toole MB, et al. Building care systems to improve access for high-risk and vulnerable veteran populations. J Gen Intern Med 2011;26 Suppl 2:683-8.

48. Hassaballa I, Ebekozien O, Ogungbadero A, Williams F, Schultz J, Hunter-Skidmore $\mathbf{J}$, et al. Evaluation of a diabetes care coordination program for African-American women living in public housing. $\mathrm{J}$ Clin Outcomes Manag 2015;22(8):365-72.

49. Eisenstat SA, Chang Y, Porneala BC, Geagan E, Wilkins G, Chase B et al. Development and Implementation of a Collaborative Team Care Model for Effective Insulin Use in an Academic Medical Center Primary Care Network. Am J Med Qual. 2016.

50. Green BB, Anderson ML, Chubak J, Baldwin LM, Tuzzio L, Catz S, et al. Colorectal Cancer Screening Rates Increased after Exposure to the Patient-Centered Medical Home (PCMH). J Am Board Fam Med 2016;29(2):191-200

51. Rosenthal MB, Alidina S, Friedberg MW, Singer SJ, Eastman D, Li Z, et al. Impact of the Cincinnati Aligning Forces for Quality Multi-Payer Patient Centered Medical Home Pilot on Health Care Quality, Utilization, and Costs. Med Care Res Rev 2016;73(5):532-45.

52. Rosenthal MB, Sinaiko AD, Eastman D, Chapman B, Partridge G. Impact of the Rochester Medical Home Initiative on Primary Care Practices, Quality, Utilization, and Costs. Med Care 2015;53(11):967-73.

53. Page TF, Amofah SA, McCann S, Rivo J, Varghese A, James T, et al. Care Management Medical Home Center Model: Preliminary Results of a Patient-Centered Approach to Improving Care Quality for Diabetic Patients. Health Promot Pract 2015;16(4):609-16.

54. Rosenthal MB, Friedberg MW, Singer SJ, Eastman D, Li Z, Schneider EC. Effect of a multipayer patient-centered medical home on health care utilization and quality: the Rhode Island chronic care sustainability initiative pilot program. JAMA Intern Med 2013;173(20):1907-13. 
55. Werner RM, Duggan M, Duey K, Zhu J, Stuart EA. The patient-centered medical home: an evaluation of a single private payer demonstration in New Jersey. Med Care 2013;51(6):487-93.

56. Fifield J, Forrest DD, Burleson JA, Martin-Peele M, Gillespie W. Quality and efficiency in small practices transitioning to patient centered medical homes: a randomized trial. J Gen Intern Med 2013;28(6):778-86.

57. Gabbay RA, Bailit MH, Mauger DT, Wagner EH, Siminerio L. Multipayer patient-centered medical home implementation guided by the chronic care model. Jt Comm J Qual Patient Saf 2011;37(6):265-73.

58. Maeng DD, Davis DE, Tomcavage J, Graf TR, Procopio KM. Improving patient experience by transforming primary care: evidence from Geisinger's patient-centered medical homes. Popul Health Manag 2013;16(3):157-63.

59. Christensen EW, Dorrance KA, Ramchandani S, Lynch S, Whitmore CC, Borsky AE, et al. Impact of a patient-centered medical home on access, quality, and cost. Mil Med. 2013;178(2):135-41. 19

60. Schmidt LA, Rittenhouse DR, Wu KJ, Wiley JA. Transforming primary care in the New Orleans safety-net: the patient experience. Med Care 2013;51(2):158-64.

61. Heyworth L, Bitton A, Lipsitz SR, Schilling T, Schiff GD, Bates DW, et al. Patient-centered medical home transformation with payment reform: patient experience outcomes. Am J Manag Care 2014;20(1):2633.

62. Hochman ME, Asch S, Jibilian A, Chaudry B, Ben-Ari R, Hsieh E, et al. Patient-centered medical home intervention at an internal medicine resident safety-net clinic. JAMA Intern Med 2013;173(18):1694-701.
63. David G, Gunnarsson C, Saynisch PA, Chawla R, Nigam S. Do patientcentered medical homes reduce emergency department visits? Health Serv Res 2015;50(2):418-39.

64. Peikes D, Zutshi A, Genevro JL, Parchman ML, Meyers DS. Early evaluations of the medical home: building on a promising start. Am J Manag Care 2012;18(2):105-16.

65. Paustian ML, Alexander JA, El Reda DK, Wise CG, Green LA, Fetters MD. Partial and incremental PCMH practice transformation: implications for quality and costs. Health Serv Res 2014;49(1):52-74.

66. Sommers BD, Epstein AM. Why states are so miffed about Medicaideconomics, politics, and the "woodwork effect". N Engl J Med 2011;365(2):100-2.

67. Yoon J, Liu CF, Lo J, Schectman G, Stark R, Rubenstein LV, et al. Early changes in VA medical home components and utilization. Am J Manag Care 2015;21(3):197-204.

68. Magill MK, Ehrenberger D, Scammon DL, Day J, Allen T, Reall AJ, et al. The cost of sustaining a patient-centered medical home: experience from 2 states. Ann Fam Med 2015; 13(5):429-35.

Publisher's Note Springer Nature remains neutral with regard to jurisdictional claims in published maps and institutional affiliations. 